\title{
Virtual Learning Communities for Faculty - does WhatsApp work?
}

\section{What problem was addressed?}

There is evidence that being part of a learning community improves teaching practice and student outcomes (1). Developing a learning community for clinical educators working over a wide geographical area, in a variety of specialities, is challenging. We attempted to address this problem by developing a virtual learning community using a smart phone app.

\section{What was tried?}

A literature search found that WhatsApp has been used in the context of medical education but not as an online learning community for educators. We considered it suitable because smart phones are nearly universal and encryption makes it secure. WhatsApp enables nominated moderators to add new members ensuring that only those invited can join.

Clinical educators in primary and secondary care who teach students from Leicester Medical School (UK) were invited by email to join a WhatsApp virtual learning community. 38 educators joined, representing a variety of locations and specialities. A year later, another group $(n=20)$ was formed specifically for educators on a new undergraduate course. These educators taught on different days of the week and did not have regular opportunities to meet others teaching the same course.

\section{What lessons were learned?}

The first group was used to post a variety of messages, including advertising events, comments about teaching sessions, feedback from conferences, developing and sharing resources, linking to published papers, reminders of deadlines, checking medical school policy and recruiting participants for research. There was an average of 1 response to each 
post. This was in contrast to the second group, which generated a mean of 6.5 responses per post. The messages in this group focussed on specific issues, with teachers providing feedback and suggestions for others to use in subsequent sessions. This group also used WhatsApp to communicate in real-time to solve problems, such as locating resources.

At the end of the year we evaluated the WhatsApp groups by inviting users to complete a survey. In addition, people who had left the first group were asked for their comments by email.

Participants responded positively to both groups. The survey demonstrated that WhatsApp groups were effective for:

- feeling more connected to the medical school;

- sharing teaching experience;

- asking questions about teaching; and

- communicating with medical school staff.

Respondents felt it was ineffective for keeping up to date in medical education. It was reportedly harder to connect with people in the larger group, which led to some attrition. Another reason for leaving was "WhatsApp overload" which affected people who were members of several WhatsApp groups.

WhatsApp appears to be an acceptable and practical way for tutors teaching on a course to develop a virtual learning community when meeting face to face is not possible. WhatsApp enabled a virtual learning community to be established, connecting tutors from a range of 
specialties and across a wide geographical area for the first time. We propose that this group may benefit from a facilitator to provide regular points for discussion.

References:

1. Vescio V, Ross D, Adams, A. A review of research on the impact of professional learning communities on teaching practice and student learning. Teaching and Teacher Education. 2008; 24: 80-91.

\section{Authors:}

Dr Emma Hayward and Dr Andrew Ward, University of Leicester. 